\title{
Sistem Informasi Administrasi Pada Puskesmas Kaliwungu Kudus Berbasis Web Dan Email Notifikasi
}

\author{
Khoiruz Zahro ${ }^{1}$, Muhammad Arifin ${ }^{2}$, Wiwit Agus Triyanto ${ }^{3}$ \\ 1,2,3 Information System, Muria Kudus University, Kudus, Indonesia Email: \\ 1khoiruzzahro19@gmail.com, 2arifin.m@umk.ac.id,3at.wiwit@umk.ac.id
}

\begin{abstract}
In managing data at the Kaliwungu Kudus Public Health Center such as patients, medical records, drug data, they still use desktop and excel-based applications so that when the computer experiences technical problems it will be prone to data loss, and when the puskesmas will hold mobile activities to the village, residents usually must wait for information from the community. village head or other apparatus so that it will increase the time in notification of information. The purpose of this research is to create an administrative system that can help collect patient data, medical recaps, drug data via the web and because this is web-based, there is no need to worry about computer problems and also notifications via email notifications so that residents who are registered at the Puskesmas will get information about activities that will be carried out by the puskesmas more quickly. With this system, it is hoped that it will make data collection at the Kaliwungu Kudus Health Center easier and also help the villagers to get information more quickly about the activities that will be carried out by the Kaliwungu Kudus Community Health Center.
\end{abstract}

Keywords: Health Center, System, Web

\section{PENDAHULUAN}

Puskesmas Kaliwungu menjadi pusat sarana pelayanan kesehatan yang berada di kecamatan Kaliwungu Kabupaten Kudus, oleh karena jumlah pasien yang relatif padat membuat kendala dalam pendataan informasi seperti data pasien, rekam medis pasien, dan juga data obat dikarenakan sistem pada puskesmas Kaliwungu Kudus masih menggunakan aplikasi berbasis desktop dan excel sehingga ketika komputer mengalami kendala teknis akan rawan terjadinya hilang data, dan ketika puskesmas akan mengadakan kegiatan keliling ke desa para warga biasanya harus menunggu info dari kepala desa

This work is licensed under a Creative Commons Attribution 4.0 International License. 


\section{Journal of Software Engineering Ampera}

Vol. 1, No. 2, June 2021 e-ISSN: 2775-2488

https://journal-computing.org/index.php/journal-sea/index

atau perangkat lainya sehingga akan menambah waktu dalam pemberitahuan informasi.

Sejalan dengan berkembangnya teknologi informasi yang cepat dan hal tersebut terbukti berperan penting dalam berbagai jenis kegiatan. Keberadaan sistem informasi mendukung kinerja peningkatan efisiensi, efektivitas, dan produktivitas bagi berbagai instansi. Untuk puskesmas Kaliwungu sendiri teknologi informasi juga berperan sangat besar untuk menunjang kegiatan sosial maupun untuk puskesmas itu sendiri.

Tujuan dilakukan penelitian ini adalah membuat sistem administrasi yang dapat membantu pendataan data pasien, rekap medis, data obat melalui web dan karena ini berbasis web maka tidak perlu khawatir akan kendala masalah komputer dan juga pemberitahuan melalui notifikasi email sehingga para warga yang terdaftar pada puseksmas akan mendapat informasi tentang kegiatan yang akan dilakukan puskesmas lebih cepat. Dengan adanya sistem ini diharapkan dapat membantu setiap pendataan yang ada pada puskesmas Kaliwungu Kudus menjadi lebih mudah dan juga membantu para warga desa agar mendapat informasi lebih cepat tentang kegiatan yang akan dilakukan oleh puskesmas Kaliwungu Kudus

\section{METODOLOGI PENELITIAN}

The method is applied to solve problems including procedures, measuring and analytical methods. Methods should make the reader able to reproduce your experiment. Provide enough detail to allow the work to be reproduced. The published method should be indicated by reference: only relevant modifications should be explained. Do not repeat details of existing methods, just refer it from the literature.

\subsection{Metode Pengumpulan Data}

Agar dapat mendapatkan data yang valid, akurat dan juga relevan maka dalam pengumpulan data penulis menggunakan cara seperti berikut.

\subsubsection{Sumber Data Primer}

Adalah data yang diperoleh langsung dari Instansi baik melalui pengamatan maupun pencatatan terhadap objek penelitian. Meliputi :

a. Observasi, yaitu melakukan pengamatan dan pencatatan terhadap 


\section{Journal of Software Engineering Ampera}

Vol. 1, No. 2, June 2021 e-ISSN: 2775-2488

https://journal-computing.org/index.php/journal-sea/index

permasalahan yang sedang diselidiki pada objek penelitian secara langsung untuk keperluan data pada Puskesmas Kaliwungu Kudus.

b. Wawancara, yaitu tanya jawab dengan pihak-pihak terkait untuk mendapatkan keterangan yang diperlukan. Misalnya bagaimana proses kegiatan ilmiah tersebut berlangsung.

\subsubsection{Sumber Data Sekunder}

Adalah data yang diambil secara tidak langsung dari objek penelitian. Data ini diperoleh dari buku-buku, dokumentasi, dan literatur-literatur. Meliputi:

a. Studi Kepustakaan, yaitu pengumpulan data dari buku-buku yang sesuai dengan tema permasalahan.

b. Studi Dokumentasi, yaitu pengumpulan data dari literatur-literatur dan dokumentasi dari internet, diktat, atau sumber informasi lain.

\subsection{Matode Pengembangan Sistem}

Model waterfall menyediakan pendekatan alur hidup perangkat lunak secara terurut. Tahapan-tahapan pada proses pengembangan sistem menggunakan waterfall ini adalah sebagai berikut:

a. Analisis Kebutuhan Perangkat Lunak

Pada tahap ini kegiatan yang dilakukan ialah pengumpulan kebutuhan yang dilakukan secara intensif untuk menspesifikasikan kebutuhan dari perangkat lunak agar dapat dipahami perangkat lunak yang bagaimana yang dibutuhkan user.

b. Desain

Desain perangkat lunak adalah proses multilangkah yang fokus pada desain pembuatan program perangkat lunak termasuk struktur data arsitektur perangkat lunak, representasi antarmuka, dan prosedur pengkodean.

c. Pembuatan Kode Program

Desain harus ditranslasikan ke dalam program perangkat lunak. Hasil dari tahap ini adalah program komputer sesuai dengan desain yang telah dibuat pada tahap desain.

d. Pengujian

Pengujian fokus pada perangkat lunak secara dari segi logik dan fungsional dan memastikan bahwa semua bagian sudah diuji. Hal ini dilakukan unuk meminimalisasi kesalahan (error) dan memastikan keluaran yang dihasilkan sesuai dengan yang diinginkan. 


\section{Journal of Software Engineering Ampera}

Vol. 1, No. 2, June 2021 e-ISSN: 2775-2488

https://journal-computing.org/index.php/journal-sea/index

e. Pendukung (support) atau Pemeliharaan (maintenance)

Tidak menutup kemungkinan sebuah perangkat lunak mengalami perubahan ketika sudah dikirim ke user. Perubahan bisa terjadi karena adanya kesalahan yang muncul dan tidak terdeteksi saat pengujian atau perangkat lunak harus beradaptasi dengan lingkungan baru. Tahap pendukung atau pemeliharaan dapat mengulangi proses pengembangan mulai dari analisis spesifikasi untuk perubahan perangkat lunak yang sudah ada, tapi tidak untuk membuat perangkat lunak baru.

\subsection{Metode Perancangan Sistem}

Proses perancangan sistem dilakukan menggunakan bahasa pemodelan UML. Unified Modelling Language (UML) adalah bahasa permodelan untuk pembangunan perangkat lunak yang dibangun dengan menggunakan teknik pemrograman berorientasi objek. UML menyajikan sejumlah visual diagram yang menunjukkan beragam aspek dalam sistem. Beberapa diagram grafis yang disediakan dalam UML diantaranya yaitu :

a. Use Case Diagram, Menjelaskan tentang kegiatan yang dilakukan oleh aktor dan sistem untuk mencapai suatu tujuan tertentu.

b. Class Diagram, Adalah diagram yang digunakan untuk menggambarkan struktur sistem dari segi pendefinisian kelas-kelas yang akan dibuat untuk membangun sistem.

c. Sequence Diagram, Menjelaskan hubungan antara komponen dalam sistem yang menghasilkan informasi berupa pesan.

d. Activity Diagram, Menggambarkan workflow (aliran kerja) atau aktivitas dari sebuah sistem atau proses bisnis.

e. Statechart Diagram, Menunjukkan kondisi yang dapat dialami atau yang terjadi pada sebuah objek.

\section{HASIL DAN PEMBAHASAN}

\subsection{Analisa Sistem Lama}

Berikut ini adalah FOD (Flow of Document) dari alur proses administrasi puskesmas. 


\section{Journal of Software Engineering Ampera}

Vol. 1, No. 2, June 2021 e-ISSN: 2775-2488

https://journal-computing.org/index.php/journal-sea/index

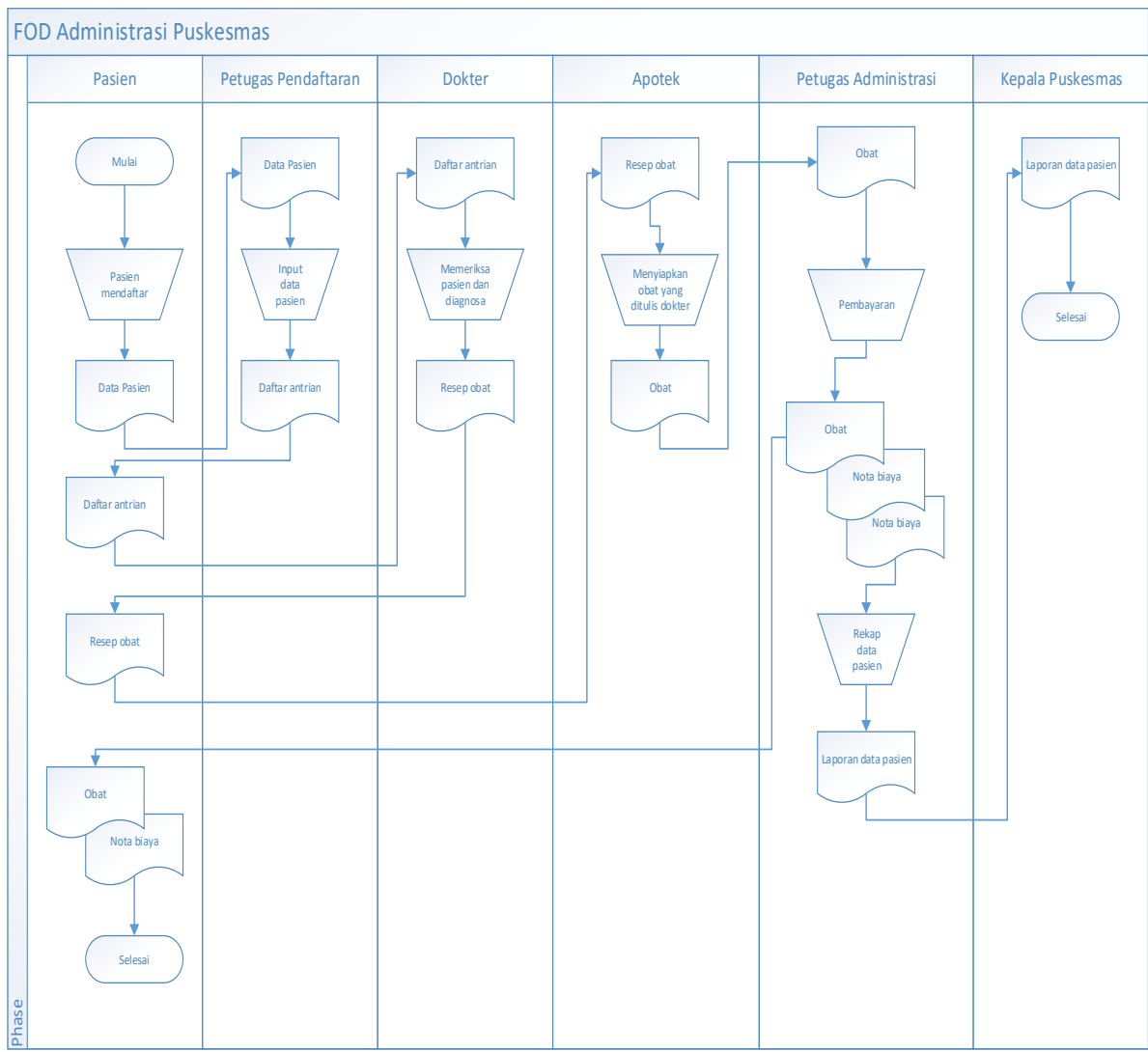

Gambar 1. Flow of Document Sistem Informasi Administrasi Puskesmas Kaliwungu

\subsection{Analisa dan Rancangan Sistem baru}

Bersumber pada proses bisnis yang ada, maka dapat diilustrasikan diagram business use case yang terwujud. Diagram Business Use Case yang terbentuk dapat dilihat pada.

\section{a. Business Use Case}

Business Use Case dari proses bisnis yang berjalan pada Puskesmas Kaliwungu dapat dilihat pada gambar dibawah ini. 


\section{Journal of Software Engineering Ampera}

Vol. 1, No. 2, June 2021 e-ISSN: 2775-2488

https://journal-computing.org/index.php/journal-sea/index

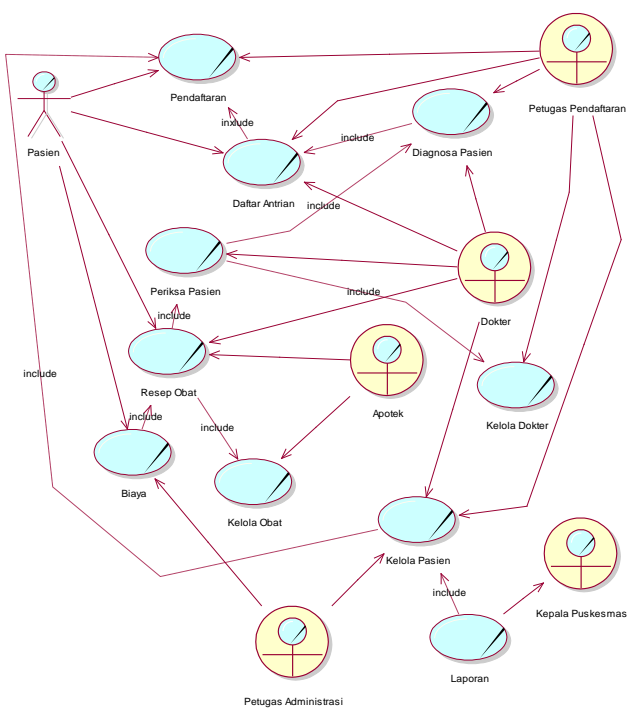

Gambar 2. Business Use Case.

b. Sistem Use Case

Sistem Use Case daripada sistem informasi administrasi Puskesmas Kaliwungu dapat dilihat pada gambar dibawah ini.

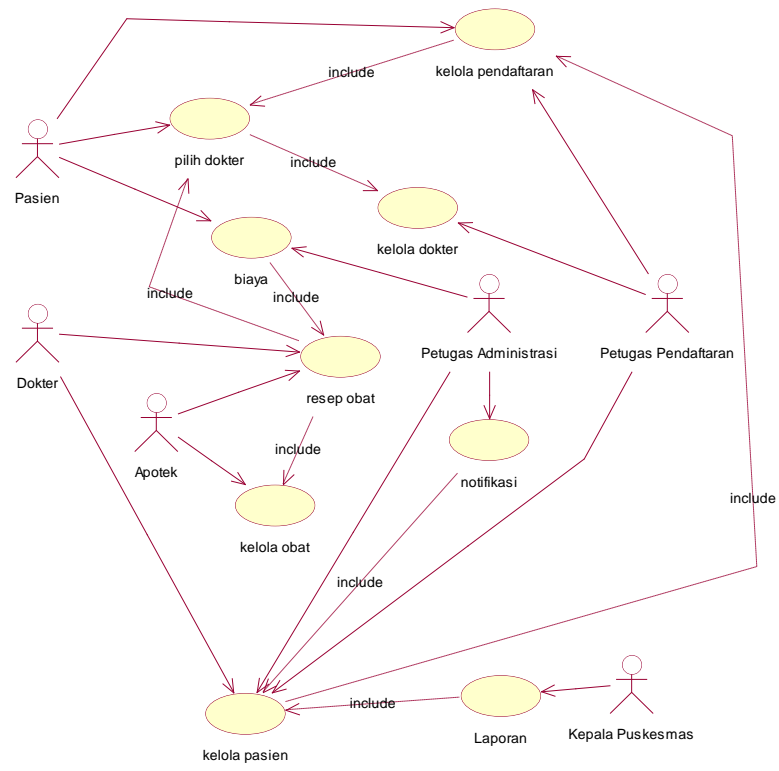

Gambar 3. System Use Case

74 | Sistem Informasi Administrasi Pada Puskesmas Kaliwungu Kudus ..... 


\section{Journal of Software Engineering Ampera}

Vol. 1, No. 2, June 2021 e-ISSN: 2775-2488

https://journal-computing.org/index.php/journal-sea/index

\section{c. Class Diagram}

Class diagram dari aplikasi administrasi Puskesmas Kaliwungu tampak digambar di bawah ini.

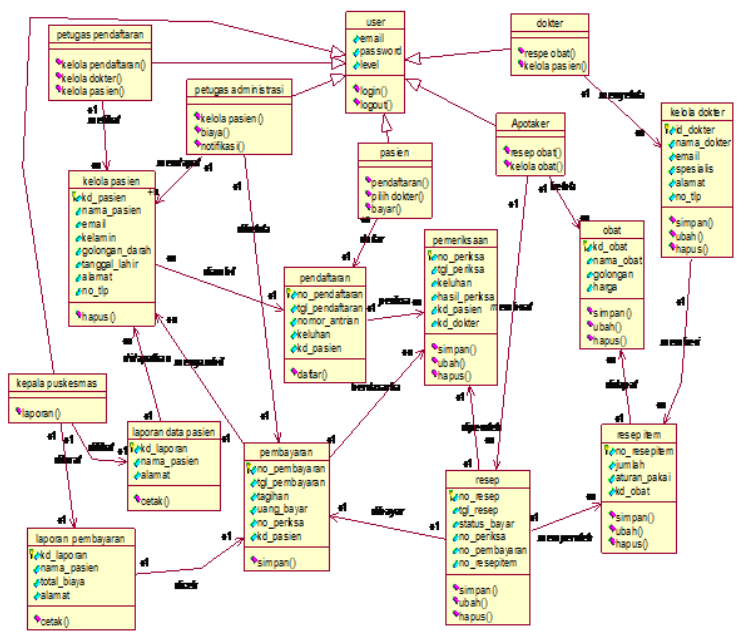

Gambar 4. Class Diagram

\section{d. Entity Relationship Diagram}

ERD dari aplikasi administrasi Puskesmas Kaliwungu tampak digambar di bawah ini.

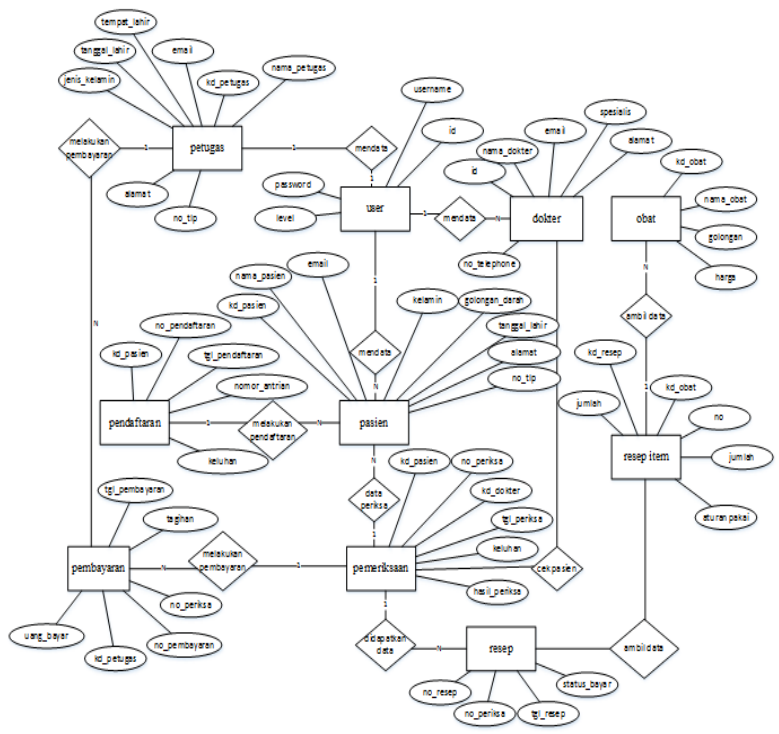

Gambar 5. ERD 


\section{Journal of Software Engineering Ampera}

Vol. 1, No. 2, June 2021 e-ISSN: 2775-2488

https://journal-computing.org/index.php/journal-sea/index

e. Relasi Tabel

Relasi tabel dari aplikasi administrasi Puskesmas Kaliwungu dapat dilihat pada gambar dibawah ini.
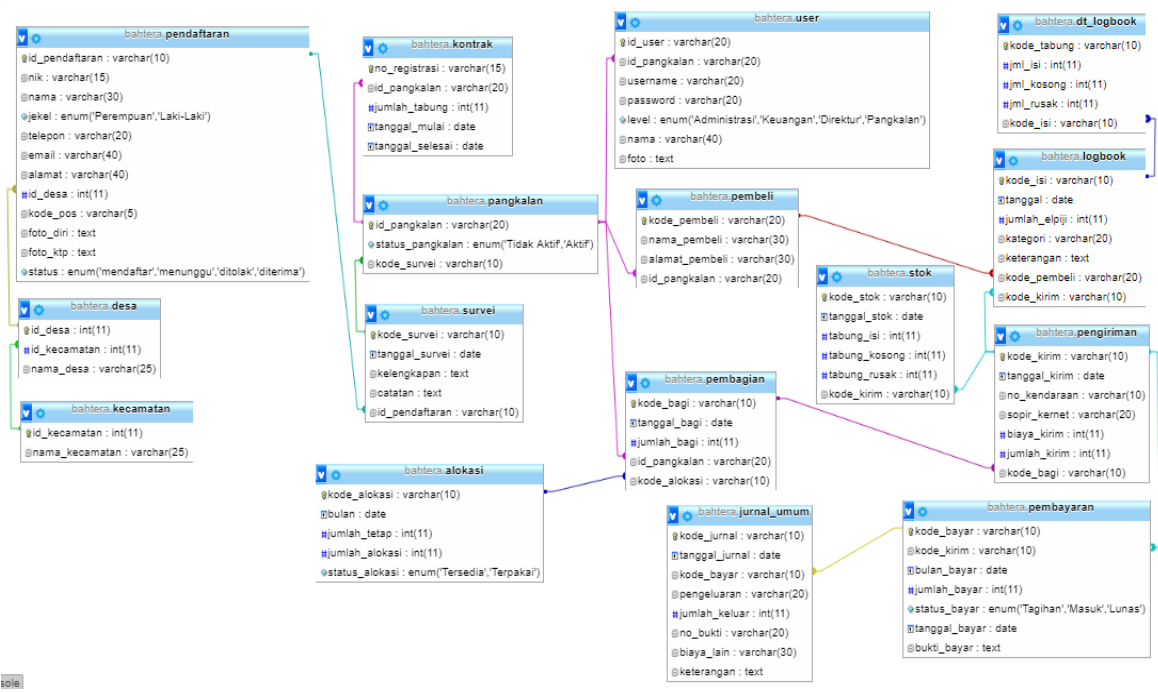

Gambar 6. Relasi Tabel

f. Halaman Pendaftaran

Tampilan dari halaman pendaftaran dapat dilihat pada gambar berikut.

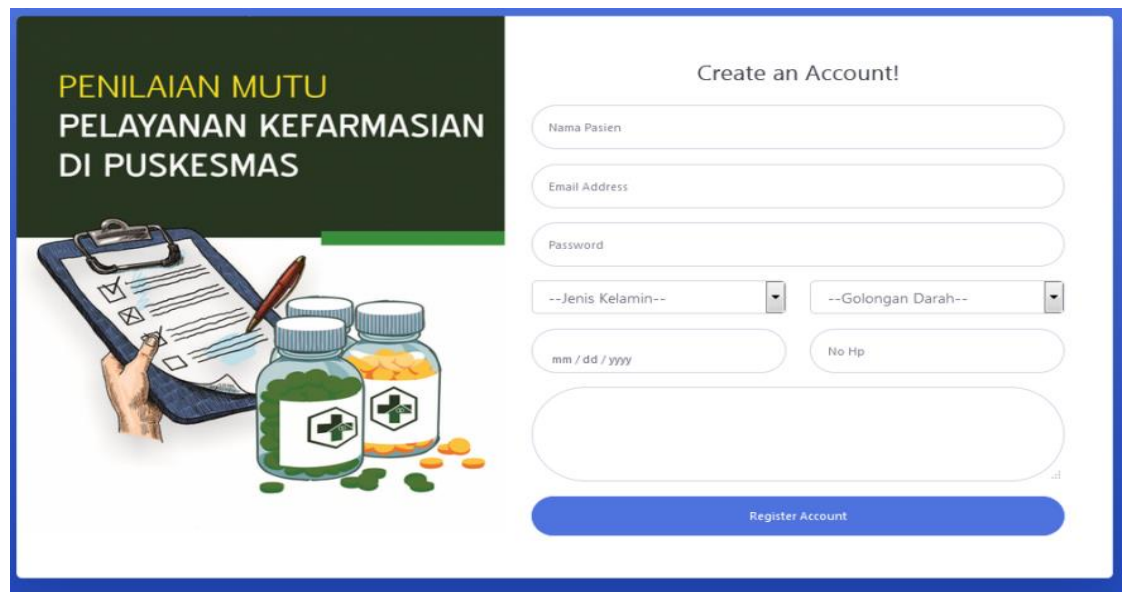

Gambar 7. Halaman pendafatran

76 | Sistem Informasi Administrasi Pada Puskesmas Kaliwungu Kudus ..... 


\section{Journal of Software Engineering Ampera}

Vol. 1, No. 2, June 2021 e-ISSN: 2775-2488

https://journal-computing.org/index.php/journal-sea/index

g. Halaman Menu Petugas

Tampilan pada menu petugas tampak digambar berikut.

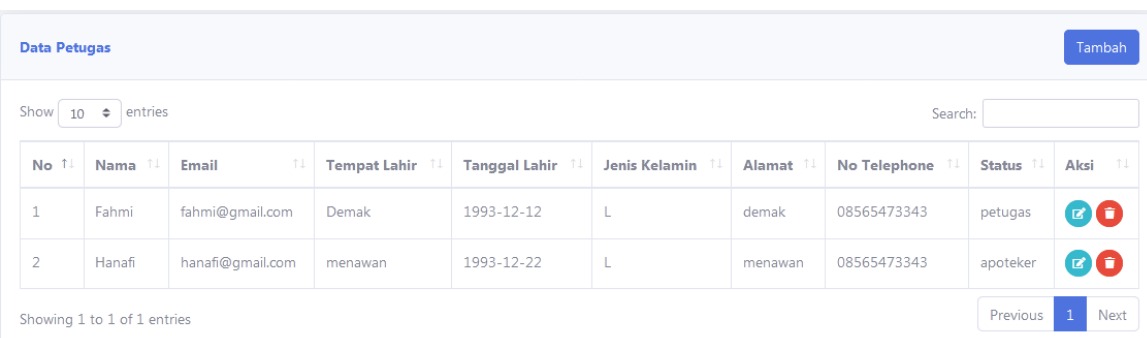

Gambar 8. Halaman Menu Petugas

h. Halaman Menu Konsultasi

Tampilan dari halaman menu konsultasi dapat dilihat pada gambar berikut.

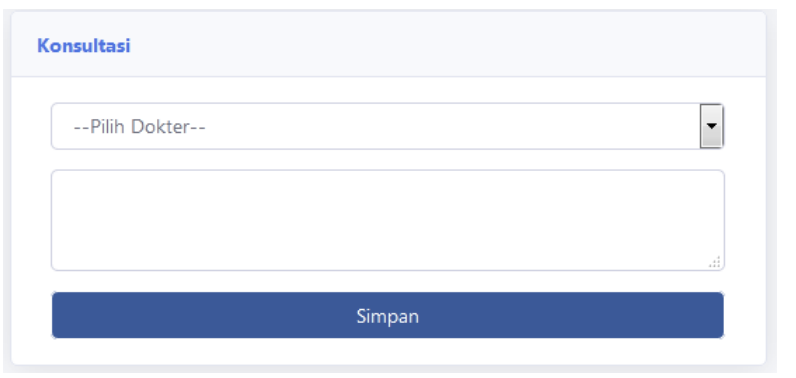

Gambar 9. Halaman menu konsultasi

i. Halaman Cetak Laporan

Tampilan dari halaman Cetak Laporan dapat dilihat pada gambar berikut.

\begin{tabular}{|c|c|c|c|}
\hline Nama Pasien & Keluhan & Tanggal Pembagararan & Iotal Bayar \\
\hline ana & gout & $2021-07.07$ & 50000 \\
\hline anammol & hikj & $2021-07-07$ & 30000 \\
\hline
\end{tabular}

Gambar 10. Halaman Cetak Laporan

\section{KESIMPULAN}

Dari hasil proses pengembangan dan perancangan serta penerapan dan pembahasan pada bab-bab yang sebelumnya telah dilakukan, maka penulis dapat mengutarakan kesimpulan anatara lain sebagai berikut: 


\section{Journal of Software Engineering Ampera}

Vol. 1, No. 2, June 2021 e-ISSN: 2775-2488

https://journal-computing.org/index.php/journal-sea/index

1. Sistem informasi administrasi puskesmas kaliwungu berbasis notifikasi email ini merupakan sistem yang dibangun dengan berlatarkan web yang dibuat menggunakan database MySql dan bahasa pemrograman PHP.

2. Sistem informasi administrasi pusksesmas ini dapat mengelola data pasien beserta notifikasi email yang akan diterima oleh pasien. Sistem ini meliputi user petugas administrasi, apotetek, dokter, kepala puskesmas dan pasien. Petugas administrasi pelaksanaan kelola data petugas, data dokter, data pasien dan data pembayaran. Dokter mengelola resep pasien yang akan diterima, dan pemeriksaan pasien. Apoteker mengelola resep obat dan stok obat.

\section{DAFTAR PUSTAKA}

[1] Dewi B.R 2020. "Perancangan Sistem Informasi Puskesmas Berbasis Web". Jurnal IKRA - ITH Informatika Vol.4 No.1, Maret 2020

[2] Fithri D.L 2018. "Aplikasi Manajemen Posyandu Untuk Peningkatan Kesehatan Ibu dan Anak".

[3] Jurnal SITECH, Vol 1 No 1 Mei 2018. Universitas Muria Kudus

[4] KBBI, 2008. Obat. Diperoleh 19 April 2021, dari https://kbbi.web.id/obat

[5] Putra M.A.H 2015. "Sistem Informasi Administrasi Pelayanan Kesehatan di Puskesmas Kiarapedes". Tugas Akhir. 2015. Universitas Kompiter Indonesia Bandung

[6] Rachman. H 2018. "Merancang Sistem Informasi Administrasi Rawat Jalan Pada Klinik Nugraha Kartika Dengan Berbasis Desktop". Jurnal IDEALIS Vol . 1 No.4, September 2018

[7] Rosa A.S., dan M. Salahuddin. 2016. "Rekayasa Perangkat Lunak Terstruktur dan Berorientasi Objek". Bandung :Informatika

[8] Sari R.E 2015. "Sistem Informasi Administrasi Pasien Rawat Jalan dan Rawat Inap Berbasis Web Pada Puskesmas Tanjung Raja". Tugas Akhir. 2015. Universitas Negri Islam Raden Fatah Palembang

[9] Sukamto R.A., dan Salahuddin, M. 2016. "Rekayasa Perangkat Lunak Terstruktur Dan Berorientasi Objek". Bandung: Informatika Badung.

[10] Sutarman, 2012. "Buku Pengantar Teknologi Informasi", Jakarta: Bumi Aksara

78 | Sistem Informasi Administrasi Pada Puskesmas Kaliwungu Kudus ..... 